\title{
ANALISIS PENGARUH INSENTIF TERHADAP PENINGKATAN PRESTASI KERJA KARYAWAN PADA PT. BANK RIAU CABANG PEMBANTU PERAWANG
}

\author{
IMRAN \\ Program Studi Kebidanan Akademi Kebidanan Salma
}

\begin{abstract}
Pt. Bank Riau is a continuation of the business activities of PT. BAPERI (PT. Riau Regional Development Bank) which was established based on the Notary Deed of Syawal Sultan No. 1 dated August 2, 1961, and the permission of the Minister of Finance of the Republic of Indonesia.No. BUM 9-4-45 dated August 12, 1961. Furthermore, with the Decree of the Governor of KDH. TK.I Riau No. 51/IV/1966 April 1, 1966, it was stated that all activities of PT. BAPERI was merged into the Riau Regional Development Bank in accordance with Law Number 13 of 1962, officially the activities of the Riau Regional Development Bank began with the status as a Bank Owned by the Government of the Riau Province. Various changes and developments in the Bank's activities, and since 1975 the status of the establishment of the Riau Regional Development Bank, Decree of the Deputy Governor of Bank Indonesia No. 5/30 / KEP.DGS / 2003 dated 22 July 2003, the legal entity status of the Riau Regional Development Bank changed from a Regional Company (PD) Regional Development Bank of Riau to a Limited Liability Company (PT). Bank Pembangunan Daerah Riau was abbreviated as PT. Bank Riau as of August 1, 2003. This research aims to Analyze the Influence of the Incentive Factor on improving the work performance of employees at PT. Bank Riau, Perawang Sub-Branch. The number of research samples are all All employees of PT. Bank Riau, Perawang Sub-Branch, as many as 60 with the sampling method saturated sampling technique or census. Saturated sampling or census is a sampling technique when all members of the population are used as samples.Meanwhile, the leadership is used as the key information in this study. Research result shows The influence of incentives on increasing work performance having a significant influence and positive means that there is a strong positive relationship between incentives and increased work performance of employees of PT. Bank Riau Perawang Sub-Branch, through regression model, the incentive variables and the indicators in the study, are able to contribute to an increase in work performance by $88.36 \%$, and the remaining $11.64 \%$ is influenced by other factors who were not examined in this study.
\end{abstract}

Keywords : Human Resources Management, Incentif, Work Performance.

Abstrak: PT. Bank Riau merupakan kelanjutan dari kegiatan usaha PT. BAPERI (PT. Bank Pembangunan Daerah Riau) yang didirikan berdasarkan Akta Notaris Syawal Sultan No. 1 tanggal 2 Agustus 1961, dan izin Menteri Keuangan Republik Indonesia No. BUM 9-4-45 tanggal 12 Agustus 1961. Selanjutnya dengan Surat Keputusan Gubernur KDH. TK.I Riau No. 51/IV/1966 tanggal 1 April 1966 disebutkan bahwa seluruh kegiatan PT. BAPERI dilebur menjadi Bank Pembangunan Daerah Riau sesuai dengan Undang-Undang Nomor 13 Tahun 1962, secara resmi kegiatan Bank Pembangunan Daerah Riau dimulai dengan status sebagai Bank Milik Pemerintah Provinsi Riau. Berbagai perubahan dan perkembangan kegiatan Bank, dan sejak tahun 1975 status berdirinya Bank Pembangunan Daerah Riau, Surat Keputusan Deputi

144 Lembaga Penelitian dan Penerbitan Hasil Penelitian Ensiklopedia $\quad$ E-ISSN: 2657-0300

P-ISSN: 2657-0319 
Gubernur Bank Indonesia No. 5/30/KEP.DGS/2003 tanggal 22 Juli 2003, secara hukum status badan usaha Bank Pembangunan Daerah Riau berubah dari Perusahaan Daerah (PD) Bank Pembangunan Daerah Riau menjadi Perseroan Terbatas (PT). Bank Pembangunan Daerah Riau disingkat PT. Bank Riau per 1 Agustus 2003. Penelitian ini bertujuan untuk Menganalisis Pengaruh Faktor Insentif terhadap Peningkatan Prestasi Kerja Karyawan pada PT. Bank Riau, Cabang Pembantu Perawang. Jumlah sampel penelitian adalah seluruh Karyawan PT. Bank Riau, Cabang Pembantu Perawang, sebanyak 60 orang dengan metode pengambilan sampel dengan teknik sampling jenuh atau sensus. Sampling jenuh atau sensus adalah teknik pengambilan sampel bila semua anggota populasi dijadikan sampel. Sedangkan informasi kunci dalam penelitian ini adalah kepemimpinan. Hasil penelitian menunjukkan Pengaruh insentif terhadap peningkatan prestasi kerja mempunyai pengaruh yang signifikan dan positif artinya terdapat hubungan positif yang kuat antara insentif dengan peningkatan prestasi kerja karyawan PT. Bank Riau Perawang Cabang Pembantu, melalui model regresi, variabel insentif dan indikator dalam penelitian mampu memberikan kontribusi terhadap peningkatan prestasi kerja sebesar 88,36\%, dan sisanya sebesar 11,64\% dipengaruhi oleh faktor lain yang tidak diteliti dalam penelitian ini. pelajaran ini.

Kata Kunci : Manajemen Sumber Daya Manusia, Insentif, Prestasi Kerja.

\section{A. Pendahuluan}

Sejalan dengan pesatnya kemajuan ekonomi dan bisnis, di dunia pada umumnya serta di Indonesia pada khususnya, kegiatan bisnis Bank Umum menjadi semakin canggih dan beraneka ragam. Walaupun demikian, berbagai macam kegiatan utama yang sejak dahulu kala menjadi tulang punggung operasi badan usaha tersebut, hingga dewasa ini masih tetap bertahan dengan kokoh. Industri perbankan telah menjadi industi yang bersifat global, sehingga dihadapkan pada kompetisi yang sangat kuat dan terbatasnya kemungkinan untuk berkembang, dalam keadaan seperti ini, maka sangat penting bagi setiap bank untuk mempunyai keunggulan kompetitif. Suatu Perusahaan baik yang besar maupun yang kecil, tidak terlepas dari faktor manusia dalam melakukan kegiatannya. Untuk menjalankan aktivitas perusahaan tersebut, maka diperlukan suatu sistem manajemen yang baik agar dapat mengkoordinir setiap kegiatan perusahaan, membina dan mengatur tenaga kerja sebagai pelaksana kegiatan perusahaan. Demikian pula dengan, dalam melaksanakan aktivitasnya perusahaan memerlukan tenaga kerja manusia yang memiliki prestasi kerja yang tinggi pada bidangnya guna mencapai suatu tujuan yang telah ditetapkan.

Faktor Sumber Daya Manusia ( SDM ) dalam suatu perusahaan memegang peran yang sangat penting disamping faktor-faktor lainnya. Dalam sebuah organisasi sangat diperlukan dan dibutuhkan manajemen yang baik agar dapat mengarahkan dan menggerakkan sumber daya manusia tersebut untuk bekerja secara maksimal, meskipun naluri, daya nalar dan tingkat sensitifitas manusia tersebut berbeda-beda. Karyawan adalah merupakan lini terdepan dari seluruh aktivitas organisasi yang bersangkutan. Untuk itu diperlukan kinerja pegawai yang tinggi serta optimal guna mendukung operasional organisasi tersebut sehingga seluruh rencana yang telah ditargetkan dapat dicapai. Untuk meningkatkan prestasi kerja dari karyawan, maka setiap pimpinan perlu memperhatikan beberapa faktor-faktor penting yang dapat mendorong peningkatan prestasi kerja karir pencapaian target serta realisasi lima tahun terakhir (2006-2010) pegawai Bank Riau Cabang pembantu Perawang dapat dikatakan cukup baik hal ini dikarenakan manajemen Bank Riau Cabang pembantu Perawang telah dapat mendorong serta memacu semangat kerja pegawai. 
Salah satu upaya untuk memotivasi pegawai yang diberikan oleh Bank Riau Cabang pembantu Perawang dalam hal ini secara nyata dapat dilihat dari pemberian kompensasi yang meliputi pemberian gaji, uang lembur, uang tunjangan, uang cuti serta THR. Selain itu manajemen Bank Riau Cabang Pembantu Perawang memberikan insentif berdasarkan SK DIR 80 per tanggal 28-09-2007 dimana insentif didasarkan hasil koreksi dan evaluasi realisasi pencapaian, yang diajukan kepada Direksi yang disesuaikan dengan kemampuan keuangan Bank, dan diharapkan dapat meningkatkan prestasi kerja sumber daya manusia yang ada untuk mendukung program-program yang menjadi tujuan perusahaan, dan diharapkan dapat menunjang visi dan misi organisasi untuk segera maju dan berkembang pesat guna mengantisipasi kompetisi global.

Insentif yang memadai diharapkan perusahaan dapat menghindari masalah masalah tentang kebutuhan para karyawannya. Dengan metode insentif di harapkan prestasi kerja karyawan dapat meningkat, sebagai salah satu proses manajemen kinerja yang dapat berfungsi sebagai motifator. Insentif yang di terapkan pada individu karyawan bertujuan untuk meningkatkan prestasi kerja karyawan untuk mengembangkan kerja sama karyawan yang baik, yang pada akhirnya akan mendorong perusahaan untuk mencapai tujuannya. Selain itu, upaya yang dilakukan oleh PT Bank Riau Cabang Pembantu Perawang antara lain kegiatan peningkatan kualitas sumber daya manusia, meliputi : memberikan kesempatan tugas belajar dan izin belajar bagi karyawannya yang ingin melanjutkan pendidikan kejenjang yang lebih tinggi, pelaksanaan pendidikan dan pelatihan (diklat) kegiatan pembinaan disiplin karyawan dan kegiatan peningkatan kesejahteraan karyawan, meliputi: peningkatan penghasilan selain insentif, seperti bonus, bantuan perawatan kesehatan, tabungan ansuransi pensiun dan pemberian penghargaan serta peningkatan kesejahteraan karyawan.

\section{B. Metode Penelitian}

Obyek penelitian adalah data langsung dari lokasi penelitian, yaitu Pada PT. Bank Riau Cabang Pembantu Perawang. Populasi dalam penelitian ini adalah seluruh karyawan PT. Bank Riau Cabang Pembantu Perawang, yang berjumlah 60 orang. Tehnik pengambilan sampel adalah sampel teknik sampling jenuh atau sensus. Sampling jenuh atau sensus adalah teknik penentuan sampel bila semua anggota populasi digunakan sebagai sampel. Jenis data dalam penelitian ini adalah data Kualitatif yaitu data yang dikumpulkan dari objek penelitian dan bukan dalam bentuk angka yang dituangkan dalam tabel, dan data kuantitatif yaitu data yang dikumpulkan dari objek penelitian yaitu berupa bentuk angka dan dituangkan dalam bentuk tabel. Sumber data adalah data primer, yaitu : data yang penulis kumpulkan langsung dari responden berupa wawancara dan kuesioner kepada karyawan PT. Bank Riau Cabang Pembantu Perawang, berupa pendapat responden tentang insentif dan prestasi kerja, dan data sekunder, yaitu : data dalam bentuk jadi yang dimilliki oleh PT. Bank Riau Cabang Pembantu Perawang, meliputi : data karyawan struktur organisasi, peraturan dan tata tertib kantor/ instansi. Teknik Pengumpulan Data melalui kuesioner, yaitu : metode pengumpulan data dengan membuat daftar pertanyaan yang diajukan kepada responden, wawancara, yaitu mengadakan tanya jawab langsung kepada responden guna memperoleh data yang diperlukan pada penelitian ini. Dalam menganalisis data penulis menggunakan metode diskriptif yaitu : mengumpulkan, memaparkan, 
menstabulasi dan dihubungkan dengan teori yang relevan dengan masalah yang dibahas kemudian penulis mengambil kesimpulan. Penilaian variabel dengan menggunakan Skala Likert untuk mengukur sikap, pendapat, dan persepsi seseorang atau kelompok tentang kejadian atau gejala sosial, yang telah ditetapkan secara sepesifik oleh peneliti dan diberi nilai sebagai berikut ( Riduwan, 2009;12).

\section{Hasil dan Pembahasan}

Analisis Pengaruh Insentif Terhadap Peningkatan Prestasi Kerja Karyawan Pada PT. Bank Riau Cabang Pembantu Perawang: Hasil pengumpulan data tentang tanggapan responden terhadap kemampuan karyawan bahwa dari 60 responden penelitian diperoleh sebanyak 20 orang atau sebesar $33.33 \%$ responden menyatakan kemampuan karyawan dalam melaksanakan aaktivitas kerja sangat baik, dan sebanyak 32 orang atau sebesar $53.33 \%$ menyatakan kemampuan karyawan Bank Riau Cabang Pembantu Perawang adalah baik, serta sebanyak 7 orang atau sebesar $11.67 \%$ responden memberikan jawaban dengan klasifikasi kurang baik, sebanyak 1 orang atau sebesar $1.67 \%$ responden memberikan jawabantidak baik, dan tidak ada responden yang memberikan jawaban pada klasifikasi sangat tidak baik.

Hasil pengumpulan data tentang tanggapan responden terhadap sikap karyawan bahwa dari 60 responden diperoleh sebanyak 15 orang atau sebesar $25.00 \%$ responden menyatakan sikap karyawan dalam melaksanakan aktivitas kerja sangat baik, dan sebanyak 38 orang atau sebesar $63.33 \%$ menyatakan sikap karyawan Bank Riau Cabang Pembantu Perawang dalam melakukan aktivitas kerja adalah baik, serta sebanyak 7 orang atau sebesar $11.67 \%$ responden memberikan jawaban dengan klasifikasi kurang baik, tidak ada responden yang memberikan jawaban pada klasifikasi tidak baik, serta sangat tidak baik.

Hasil pengumpulan data tentang tanggapan responden terhadap kualitas kerja karyawan bahwa dari 60 responden diperoleh sebanyak 20 orang atau sebesar 33.33 $\%$ responden menyatakan kualitas kerja karyawan sangat baik, sebanyak 35 orang atau sebesar $58.33 \%$ menyatakan kualitas kerja karyawan Bank Riau Cabang Pembantu Perawang adalah baik, serta sebanyak 5 orang atau sebesar $8.34 \%$ responden memberikan jawaban dengan klasifikasi cukup baik, tidak ada responden yang memberikan jawaban pada klasifikasi tidak baik, serta sangat tidak baik.

Dari perhitungan diperoleh persamaan regresi liniernya untuk (variabel $\mathrm{X}$ ) dan (variabel $\mathrm{Y}$ ) yaitu $\mathrm{Y}=12.19+0.02 \mathrm{x}$, yang berarti koefisien arah variabel $\mathrm{X}(\mathrm{b})$ adalah positif, dimana setiap kenaikan/penurunan variabel insentif menyebabkan kenaikan/penurunan sebesar 0.02 satuan terhadap prestasi kerja karyawan.

Dari perhitungan diketahui sebesar $0,94 \%$ positif. Oleh sebab itu korelasi antara kedua variabel diatas yaitu dari hasil penelitian tentang insentif terhadap prestasi kerja karyawan Bank Riau Cabang Pembantu Perawang bersifat searah. Yang bararti ada pengaruh antara insentif dengan prestasi kerja, koefisien determinasi keseluruhan ( $\mathrm{R}^{2}$ ) sebesar 0.8836 menunjukkan bahwa model regresi linier ini variabel insentif mampu memberikan kontribusi terhadap peningkatan prestasi kerja sebesar $88.36 \%$, dan sisanya sebesar $11.64 \%$ lagi dipengaruhi oleh faktor lain yang tidak diteliti dalam penelitian ini.

\section{Penutup}

Secara umum sistem insentif yang berlaku dalam rangka meningkatkan prestasi kerja karyawan PT . Bank Riau Cabang Pembantu Perawang, sudah dinilai sesuai oleh sebagian besar karyawan, Sesuai didasarkan pada kecakapan, keahlian, E-ISSN: 2657-0300 Lembaga Penelitian dan Penerbitan Hasil Penelitian Ensiklopedia $\quad 147$ P-ISSN: 2657-0319 
pengalaman, karyawan yang selalu terdorong melakukan pekerjaan untuk mencapai kinerja yang optimal, yang menjadi tanggung jawabnya. Hasil dari tanggapan responden menunjukkan bahwa kemampuan karyawan, sikap karyawan, dan kualitas kerja karyawan Bank Riau Cabang Pembantu Perawang dalam melakukan segala aktivitas kerjanya sebagian besar adalah baik dan ini juga menunjukkan bahwa karyawan semakin mampu dalam mengembangkan diri serta memanfaatkan sarana yang ada di sekitarnya, dapat bekerja secara efektif dan efisien, terdapat kebutuhan untuk realisasi diri atau aktualisasi diri berupa kebutuhan individu untuk merealisasi potensi dan skill yang ada pada dirinya untuk mencapai pengembangan diri secara berkelanjutan dan untuk menjadi lebih kreatif, ekspresi diri akan melakukan yang terbaik serta dapat menyelesaikan pekerjaannya sendiri, memberi penilaian dan kritikan terhadap sesuatu. Insentif memiliki pengaruh yang positif dan signifikan terhadap peningkatan prestasi kerja karyawan PT.Bank Riau Cabang Pembantu Perawang. Untuk meningkatkan prestasi kerja yang lebih baik maka PT . Bank Riau Cabang Pembantu Perawang, perlu memperhatikan dan menyadari pentingnya pemberian insentif, serta penyempurnaan sarana dan prasarana kerja yang memadai sehingga kendala dalam pelaksanaan kerja dapat dihindari. Mengarahkan pengembangan yang mengacu pada loyalitas profesi, untuk menumbuhkan rasa bangga serta mencintai profesinya, dengan orientasi mencapai prestasi yang tinggi dan hasil kerja yang bermutu, dengan meingikutsertakan atau mengirim karyawan ke berbagai diklat, atau seminar-seminar yang berhubungan dengan job descreption karyawan yang bersangkutan. Meningkatkan prestasi kerja karyawan dengan menciptakan sistem insentif dalam bentuk lain, untuk lebih meningkatkan kinerja, karena banyak faktor-faktor yang mempengaruhi peningkatan kinerja pegawai, untuk waktu yang akan datang diharapkan lebih memperhatikan bentuk dan sistem insentif yang sesuai yang berpengaruh baik terhadap kinerja karyawan, serta memberikan peluang yang lebih banyak pada karyawan untuk dapat menambah pengalaman, pengetahuan dan meningkatkan keahlian pada bidangnya serta diberikan kesempatan bagi pegawai untuk mengikuti pendidikan secara formal kejenjang yang lebih tinggi.

\section{Daftar Pustaka}

Agus Suryana, 2005, Seni Membangkitkan Kesadaran Dan Semangat Kerja Karyawan Ditempat Kerja, Jakarta, Penerbit progress

A. Usmara Msi,2002, Paradigma Baru manajemen Sumber daya Manusia, Yogyakarta, Amara Books.

Ernie Tisnawati Sule dan Kurniawan Saefullah, 2006, Pengantar Manajeman Jakarta, Prenada Media.

Eugene Mc Kenna \& Nic Beech, 2002, Manajemen Sumber Daya Manusia, Yogyakarta, Penerbit Andi.

Fautisno Cordoso Gomes, 2009, Manajemen Sumber Daya Manusia, Yogyakarta, Penerbit Andi

Hasibuan Malayu SP. 2007, Manajemen Sumber Daya Manusia, Jakarta , PT Bumi Aksara

Handoko. T. Hani 1997, Manajemen Personalia dan Sumber Daya Manusia, Yogyakarta, BPFE

H., Hadari Nawawi ; 2005, Manajemen Sumber Daya Manusia Untuk Bisnis Yang Kompetitif , Gadjah Mada Press, Yogyakarta 


\section{3, Perencanaan SDM untuk Organisasi Profit yang}

Kompetitif. Yogyakarta, Gadjah Mada Press.

Heidjrahman Suad Husnan, 2000, Manajemen Personalia, Yogyakarta. BPFE.

Ishak Arep dan Henri Tanjung,2003, Manajemen Motivasi, Jakarta, PT Gramedia Widiasarana Indonesia.

Manulang, M dan Marihot AMH Manulang. 2008, Manajemen Personalia. Gadjah Mada Universitas Press, Yogyakarta.

Nurmansyah, 2007, Manajemen Sumber Daya Manusia, Cet I, Pekanbaru Unilak Press.

, 2008, Manajemen Sumber Daya Manusia Strategik Untuk Meraih Keunggulan Kompetitif Perusahaan, Cet I, Pekanbaru Unilak Press.

Riduwan, 2009, Skala Pengukuran Variabel-Variabel Penelitian. Bandung, Penerbit Alfa Beta

Robert L. Mathi dan Jhon H. Jackson, 2001, Manajemen Sumber Daya Manusia, Jakarta Salemba Empat.

Sedarmayanti. Manajemen Sumber Daya Manusia Reformasi Birokrasi dan Manajemen Pegawai Negri Sipil, Bandung. Penerbit. PT. Rafika Aditama

Sukanto Reksohadiprodjo dan T Hani Handoko , 2001, Organisasi Perusahaan , Yogyakarta . BPFE

Siagian, SP, 2002, Manajemen Sumber Daya Manusia, Jakarta, PT. Bumi Aksara

Siswanto, 2006, Pengantar Manajemen, Jakarta, PT Bumi Aksara.

Sri Indrastuti dan Amries Rusli Tanjung, 2008, Peran Budaya Organisasi, Kepuasan Kerja, Komitmen Kerja Dan Kinerja Pegawai Serta Kualitas Pelayanan, Secara Teoritis Dan Empiris, Pekanbaru UIR Press.

Tjutju Yuniarsih dan Suwatno, 2009, Manajemen Sumber Daya Manusia, Teori , Aplikasi dan Issu Penelitian Bandung. Penerbit Alfa Beta

Veithzal Rivai da Ella Jauvani Sagala, 2009, Manajemen Sumber Daya Manusia Untuk Perusahaan, Jakarta, Penerbit rajawali Pers 